\title{
Erkenne dich selbst
}

Liebe Leserinnen, liebe Leser,

dieser Spruch ist eine der überlieferten antiken Weisheiten. Er befand sich am ApollonHeiligtum von Delphi'. Er wurde dem Gotte zugeschrieben. Wie er unter die Menschen kam, ist umstritten. Eine Version, die den göttlichen Ursprung plausibel macht, ist: Chilon von Sparta, einer der Sieben Weisen, habe ihn als Orakelspruch von der delphischen Pythia, Apollons Priesterin, erhalten. Er habe vom Gotte wissen wollen, was die Menschen zuvorderst lernen sollten. Der Spruch war die verdächtig plausible Antwort des Gottes. Wie alle delphischen Orakelsprüche fand er viel Beachtung. Verstanden wurde er als eine Aufforderung an den Menschen - nicht nur an Chilon - seinen Verstand zu bemühen, seine Grenzen zu erkennen, auferlegte Beschränkungen hinzunehmen, vor allem zu begreifen, dass nur die Götter unsterblich sind und der Mensch ihrer Willkür und dem Schicksal ausgeliefert ist. Also eine eher pessimistische Auslegung. Erst in der späten Antike etwa bei Cicero - kam der Gedanke auf, dass man beim Sich-selbst-Erkennen auch etwas Gutes entdecken könnte, mit dem sich das Leben angenehmer gestalten ließe. Es blieb aber lange bei der frommen pessimistischen Auslegung. Außerdem ist zu bedenken: Das alles liegt lange zurück. Die Menschen der Antike dachten nicht modern, nicht an Selbstverwirklichung. Sie richteten ihr Erkennen mehr auf die Rolle des Selbst unter Göttern, Polis und Familie. Sie standen zu dem Spruch des Gottes anders als wir heute.

Für moderne Menschen ist das nicht leicht zu verstehen. „Erkenne dich selbst“ wäre nach heutigem Verständnis ein Appell an den Menschen, nach seinen privaten Eigenschaften und Interessen zu suchen. Er muss dazu im Abstand zum Suchbereich einen Standpunkt einnehmen. Was er von da aus erkennt, hängt vom Aspekt des Standpunkts ab. Ob es sein Ehrgeiz, sein Gewissen oder sein Verständnis „politischer Korrektheit“ ist, ob optimistisch oder depressiv unterlegt: Es liefert ihm unterschiedliche Resultate. Dieser Selbsterkenntnis fehlte es insofern an Objektivität. Der Mensch ist kein objektiver Erkenner seiner selbst.

Dem kann aber neuerdings abgeholfen werden. Der Mensch unserer Tage ist messbar. Er kann sich sogar selbst vermessen; siehe Anmerkung ${ }^{2}$. Er legt geeichte mobile Messgeräte an, lässt sie seine Körperfunktionen erfassen, sammelt die Messwerte und wertet diese per Computer zu weiteren Erkenntnissen aus. Das erfolgt neuerdings in Anwendergruppen. Man teilt der Gruppe die gemessenen Daten mit, vergleicht die eigenen mit den Messwerten anderer und mit empfohlenen Normwerten. Wenn eine Messung enttäuscht, tut man etwas, um den Wert aufzubessern, etwa weniger essen, härter trainieren, so lange bis der eigene Körper akzeptable Messwerte produziert. So hält sich der Mensch bei Kraft und Gesundheit und - mens sana in corpore sano - seinen Geist bei Verstand. Das dankt er nicht nur seiner Selbsterkenntnis, sondern auch dem Mitwirken der Anwendergruppe. An ihr gespiegelt erfährt er Zutreffenderes über sich selbst, als Apollon je gemeint hätte. Mit professioneller Unterstützung kann der Mensch sich selbst erkennen - objektiv, quantifiziert, standardisiert, dokumentiert. Er nimmt freilich in Kauf - oder er schätzt es gar - dass seine Daten kommuniziert werden. Wie es im hier zitierten DuD-Beitrag heißt: nach der Devise „vermiss dich selbst und teile es allen mit"; oder in Erweiterung des apollinischen Spruchs: „Erkenne dich selbst und gib dich zu erkennen."

Nun im Ernst, liebe Leserinnen und Leser: Dieses quantifizierte Sich-selbst-Erkennen fördert Selbsterkenntnisse zu Tage, zuhauf. Quantifiziert, wie es anfällt, lässt es sich präzisieren und kommunizieren. Aber es ist höchstwahrscheinlich nicht das, woran seinerzeit Apollon gedacht hatte. Es fehlt ihm der Nimbus des Gottes; die Kommunikation macht es anfällig; es braucht Datenschutz.

Mit freundlichen Grüßen, Ihr

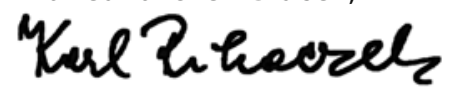

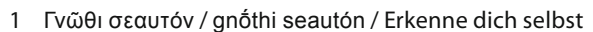

2 Marit Hansen, Zukunft von Datenschutz und Privatsphäre in einer mobilen Welt, Seite 435 „4 Selbstvermessung: Quantified Self", DuD 07/15 